MEDEIROS, Aline da Silva. A dinâmica hospitalar da Maternidade Dr. João Moreira, em Fortaleza, nas primeiras décadas do século XX. História, Ciências, Saúde - Manguinhos, v.20, n.3, jul.-set. 2013, p.963-981.

\section{A dinâmica hospitalar da Maternidade Dr. João Moreira, em Fortaleza, nas primeiras décadas do século XX}

\section{The hospital dynamics at} Maternidade Dr. João Moreira, Fortaleza, in the early decades of the twentieth century

\author{
Aline da Silva Medeiros \\ Doutoranda do Programa de Pós-graduação em História Social/ \\ Universidade Federal do Ceará. \\ Rua Onofre Sampaio Cavalcante, 284 \\ 60821-820 - Fortaleza - CE - Brasil \\ linemedeiros@gmail.com
}

Resumo

A Maternidade Dr. João Moreira, primeiro hospital dedicado a mulheres em Fortaleza, foi criada em março de 1915. Seus objetivos eram diminuir os índices de mortalidade durante o parto e inserir o corpo feminino como objeto da prática médica em Fortaleza. Para isso, disponibilizava suas enfermarias tanto para o atendimento das mulheres da cidade quanto para a realização de curso de formação de parteiras. Neste trabalho, analisamos dinâmicas internas dessa instituição: sua organização espacial, seus regimes de cura e disciplina, sua relação com as pacientes, sua equipe hospitalar etc. A consulta de registros estatísticos e de casos clínicos produzidos por médicos auxiliou o estudo desse que foi um dos principais marcos do desenvolvimento da obstetrícia no Ceará.

Palavras-chave: parto; hospital; obstetrícia; Fortaleza; parteiras.

Abstract

Maternidade Dr. João Moreira, the first women's hospital in the Brazilian city of Fortaleza, was founded in March 1915. It was created with the goal of reducing infant mortality during childbirth and made the female body an object of medical practice in the city. Its wards were used not just by the city's womenfolk, but also for midwife training courses. In this study, we analyze the dynamics inside the institution: its spatial organization, its healing and disciplinary methods, its relationship with its patients, its medical staff, etc. Statistical records and clinical case studies produced by doctors were important sources of research in this, one of the first initiatives in the development of obstetrics in the state of Ceará.

Keywords: childbirth; hospital; obstetrics; Fortaleza; midwives. 
$\mathrm{C}$ omo indica boa parte dos textos publicados na revista Ceará Médico ${ }^{1}$, na capital cearense, as preocupações médicas em torno da natimortalidade e também da mortalidade materna na ocasião do parto ganhavam força desde os anos 1910. O saldo significativo de mortes durante o nascimento foi visto pelos médicos da cidade como decorrência direta das práticas que moviam as assistências ao parto realizadas pelas parteiras 'curiosas' - mais conhecidas pela população local como comadres ou aparadeiras. Publicando na revista do Centro Médico Cearense uma série de casos em que as assistências ao parto das comadres culminavam em corpos mortos, mutilados, doentes e disformes, os médicos de Fortaleza faziam uma lista sempre crescente de práticas 'curiosas' consideradas descabidas, cujas consequências eram sempre as mais desastrosas.

Nos anos 1920, por exemplo, o doutor Cesar Cals (1928, p.10) registrava que, quando eram as aparadeiras que assistiam ao parto, "a mortinatalidade e a mortalidade fetal eram assombrosas e dominavam a cena, nas parturientes, as hemorragias e infecções puerperais". Na década seguinte, o doutor Virgílio de Aguiar (dez. 1933, p.33), reafirmando a associação entre natimortalidade e assistência das comadres, observava:

Em dias de novembro último, tive um caso desta espécie; o médico que faz obstetrícia no Brasil sabe que eles andam em barda - a natimortalidade rotulando feto morto em trabalho de parto, por distocia descurada, por imperícia ou ignorância da parteira ou aparadeira.

...

Deixando eu o consultório com urgência, ao chegar à casa da parturiente já era sem tempo, pois afinal a parteira havia extraído o feto (uma robusta criança) que estava morta

Acontecimento que, segundo os médicos, não raras vezes culminava com a morte ou doença de crianças e mulheres, o momento do nascimento foi considerado pelos médicos da cidade evento problemático e, por isso mesmo, propício à instauração de condutas biopolíticas, ou seja, comprometidas com a promoção da vida (Foucault, 2007). Tratava-se, nesse sentido, de fazer da parturição uma experiência produtiva, cujo corolário, a saber, a vida e a saúde de crianças e mulheres, se coadunava com os supostos anseios republicanos, então propalados pela imprensa, de obter população numerosa e sadia, empenhada no fomento de riquezas e no alcance do progresso da nação.

Segundo os médicos de Fortaleza, a invenção do parto como um problema não se referia apenas às vidas que uma assistência dita descabida poderia vir a desperdiçar, mas também dizia respeito ao corpo no qual o nascimento tinha sede.

A historiografia da medicina da mulher há tempos vem chamando a atenção para o protagonismo do corpo na elaboração das relações de poder que durante muito tempo intentaram controlar as existências femininas. Fabíola Rohden, por exemplo, enfatiza o surgimento, a partir do século XVIII, da ciência sexual como produtora das diferenças entre homens e mulheres. A autora explica que, segundo esse domínio científico,

Homens e mulheres seriam naturalmente distintos nas suas características físicas e também nas suas características morais ou psicológicas. Além disso, as qualidades atribuídas a cada um e as suas funções sociais são descritas com o mesmo grau de determinismo das suas funções fisiológicas. O gênero parecia irremediavelmente colado ao sexo em uma única e invariável direção (Rohden, 2001, p.12). 
Embasados nas características sexuais, os homens de ciência atribuíram às mulheres um destino natural eminentemente comprometido com a reprodução. O corpo, aqui entendido em sua acepção atrelada ao sexo, centralizava a vida das mulheres e se colocava como empecilho para outras formas de subjetivação que não estivessem envolvidas com a maternidade, considerado o momento alto da existência das mulheres.

Para Ana Paula Vosne Martins (2004, p.100), essa relação entre características sexuais e o destino irremediável de ser mãe ganhou força a partir do desenvolvimento da chamada ciência dos partos:

Os obstetras foram os primeiros a levar adiante o modelo biológico das diferenças sexuais estabelecido no século XVIII pelos anatomistas e fisiologistas. Seu foco de análise se fechou sobre as estruturas e os processos que eles consideravam ser a explicação para a natureza feminina e a justificação materialista dos papéis sociais das mulheres.

Ao reforçar as diferenças sexuais e, por tabela, os papel social a que se destinavam as mulheres, a moderna obstetrícia tratou de 'patologizar' o corpo feminino, inserindo-o numa natureza permanentemente instável: "a sua existência normal se apresenta mesmo como uma patologia estabelecida, manifestada nas gravidezes e 'hemorragias periódicas'” (Rohden, 2001, p.16) e, principalmente, nos partos.

Assim, para os médicos da capital cearense, como de resto para os médicos brasileiros, evento naturalmente arriscado, já que a própria natureza feminina era perigosa e ameaçadora, o parto deveria, pois, ser acompanhado por agentes legitimados por instituições científicas, oficialmente aptos a fazer a natureza seguir seu próprio curso. Caso contrário, ou seja, quando as assistências ao parto eram encaminhadas por parteiras 'curiosas', como já mencionado, reinariam os citados altos índices de natimortalidade e mortalidade materna. A assistência ao parto, nesse sentido, constituiu momento estratégico para a inserção do corpo feminino na prática médica então em ascensão em Fortaleza.

Encaminhada por agentes legitimados por instituições científicas, a assistência ao parto repercutiria positivamente entre os interessados em fazer progredir a jovem nação brasileira. Se o progresso de uma nação se media pelas riquezas que sua população saudável e numerosa era capaz de produzir, o gerenciamento da reprodução a partir do corpo feminino, em especial do parto, era condição sine qua non para a elevação dos índices de natalidade e de saúde de um país.

Nesse sentido, a fundação da Maternidade Dr. João da Rocha Moreira, o primeiro estabelecimento hospitalar do gênero em Fortaleza, expressou importante marco local da invenção do parto como problema, cujas soluções, por sua vez, passava a assumir. Empenhada na reorganização da assistência ao parto na capital cearense, a instituição dividiu-se em duas frentes de trabalho interligadas: a série de atendimentos médicos dedicados às mulheres, na maioria gestantes, parturientes e puérperas, que teriam enfermarias próprias; $\mathrm{e}$ as atividades que compunham o Curso de Parteiras Diplomadas, empreendimento pedagógico que promovia a formação obstétrica de mulheres interessadas em ter na assistência domiciliar ao parto uma profissão - a de 'parteiras diplomadas'.

A incumbência de reorganizar a assistência ao parto reuniu, portanto, em torno da Maternidade Dr. João Moreira o escopo triplo de diminuir os índices de natimortalidade 
e mortalidade materna na ocasião do nascimento, de inserir o corpo feminino na prática médica cearense e, por tabela, de difundir preceitos científicos entre as mulheres da capital, em especial as noções de puericultura que constituiriam as bases de uma 'maternidade científica', como se verá adiante.

\section{Organização espacial e funcionamento do serviço obstétrico}

No alvorecer do século XX, o doutor Manuelito Moreira, médico cearense formado em 1906 pela Faculdade de Medicina do Rio de Janeiro, então estabelecido em Fortaleza, lançava a ideia de fundar a primeira maternidade da cidade. Em homenagem ao seu pai recém-falecido, a instituição hospitalar chamar-se-ia Maternidade Dr. João da Rocha Moreira. O projeto foi desde logo abraçado por um conjunto de senhoras da alta sociedade local. Comprometidas com o dever filantrópico de arrecadar fundos para a futura maternidade, essas senhoras organizaram, em janeiro de 1915, a Sociedade Mantenedora da Maternidade Dr. João Moreira. Por entendimento entre essa sociedade, gerenciada pelo doutor Manuelito Moreira, e a Irmandade da Misericórdia, a maternidade foi inicialmente instalada nas dependências da Santa Casa de Fortaleza, em cujo prédio, situado na praça dos Mártires, perímetro central da cidade, funcionou desde sua inauguração, em 19 de março de 1915, até 1929, quando se transferiu para sede própria.

Na capital cearense, antes de sua criação, o atendimento hospitalar dispensado a gestantes, parturientes e puérperas era realizado nas enfermarias de cirurgia da Santa Casa de Misericórdia, nas palavras do doutor Cesar Cals (1935, p.3), "de permeio com outros doentes". Com a organização de um serviço obstétrico nas dependências do Hospital da Misericórdia, o conjunto das mulheres às voltas com o parto que chegava a esse estabelecimento não mais dividiria espaço com os demais pacientes em atendimento, mas, encaminhado para a Maternidade Dr. João Moreira, seria tratado em enfermarias exclusivamente obstétricas.

Em 1928, quando a instituição ainda estava alojada no prédio da Santa Casa de Misericórdia, o doutor Cesar Cals (set. 1928, p.9), então seu diretor, publicava na revista Ceará Médico uma resenha sobre o funcionamento do serviço obstétrico. Do ponto de vista estrutural, o médico informava que

Além de outras dependências indispensáveis a qualquer serviço hospitalar, a Maternidade tem à sua disposição: uma sala para gestantes, uma para puérperas, uma para infectadas, uma ampla sala de operações com abundante instrumental cirúrgico, um quarto para partos, uma sala para operadas e um gabinete médico - Dispõe de 26 leitos e 8 berços - 12 leitos para gestantes, 6 para puérperas, 4 para infectadas e 4 para operadas.

Chegadas às dependências da Maternidade Dr. João Moreira, algumas pacientes eram recebidas no gabinete médico, compartimento em que eram submetidas aos primeiros exames. A depender de seu estado de saúde, as mulheres eram encaminhadas ou para a sala das gestantes, ou para a sala das puérperas, ou para a sala das infectadas. Desse modo, a organização interna do serviço obstétrico revela que não se intentava apenas recolher as gestantes, parturientes e puérperas que recorriam ao Hospital da Misericórdia, mas, uma vez na Maternidade, essas mulheres recebiam, ademais, nova distribuição espacial conforme suas 
condições corporais específicas, procedimento esse considerado imprescindível para a eficácia das mais diversas práticas terapêuticas.

Manifestados os sinais da parturição, as gestantes ali internadas eram conduzidas para o quarto de partos, onde a assistência ao nascimento era realizada de forma individualizada. Tendo dado à luz, as pacientes eram transferidas para a sala das puérperas, onde se restabeleciam dos trabalhos da parturição. Caso apresentassem os sintomas da infecção puerperal, moléstia então causada pela invasão de microrganismos patogênicos no aparelho genital durante o parto, as pacientes eram alocadas na sala das infectadas, na qual, longe das demais puérperas - que deveriam manter-se preservadas de sua ameaça -, recebiam tratamentos adequados. As salas das gestantes, das puérperas e das infectadas podiam figurar como destinos únicos de algumas mulheres que recorriam à Maternidade Dr. João Moreira. Assim, se uma mulher grávida apresentasse pequenos distúrbios de tratamento simples, podia receber alta antes do parto, tendo permanecido unicamente na sala das gestantes. Caso uma mulher chegasse ao serviço obstétrico portando alguma complicação do pós-parto diferente da infecção puerperal, era encaminhada diretamente à sala das puérperas, onde permaneceria até o alcance da cura. A sala das infectadas, por seu turno, não raras vezes, constituiu o destino único de diversas pacientes que, paridas em casa, já chegavam à Maternidade manifestando os sintomas da febre puerperal.

Era na sala de operações que os médicos realizavam procedimentos corporais mais profundos, para o que faziam uso de instrumental cirúrgico especializado. Na resenha dedicada às dinâmicas do serviço obstétrico, o doutor Cesar Cals (set. 1928, p.9) informava que, até 1928,

À exceção da cesariana, todas as operações obstétricas têm sido executadas na Maternidade, desde as múltiplas variedades de embriotomia [mutilação fetal] até a simples extração de placenta. Várias laparotomias [incisão da parede abdominal] e histerectomias [remoção do útero] têm sido feitas nos serviços da Maternidade, pela mão segura e destra do abalizado cirurgião Dr. José Frota, meu excelente amigo e companheiro de serviço. Entre as múltiplas operações de ventre, ocorre-me citar, como das mais importantes, uma extração de um fibroma [tumor] uterino, com 12 quilos de substância sólida e 6 litros de líquido, e uma outra feita em uma prenhez abdominal com 10 meses, sendo extraído um enorme cisto intacto, dentro do qual havia um feto morto de tamanho normal.

Desse modo, além da série de intervenções propriamente obstétricas, se realizavam igualmente na Maternidade Dr. João Moreira operações em mulheres fora do estado de prenhez, indicando, pois, que o serviço obstétrico estava também disponível para o atendimento de casos clínicos de natureza ginecológica. Depois de submetidas a operações, fosse por ocasião do parto ou por conta de outras complicações no ventre, as pacientes eram remanejadas para a sala de operadas, compartimento em que recebiam os cuidados próprios ao período pós-operatório.

Em resenha publicada na revista Ceará Médico referente ao mês de fevereiro de 1933, o doutor Cesar Cals (fev. 1933, p.6) informava que, desde 1929, a instituição havia sido transferida da Santa Casa de Misericórdia para prédio próprio, localizado na praça Comendador Teodorico, mais conhecida como praça da Alagoinha - ainda nas proximidades do perímetro central da cidade. A partir de então, detalhava o médico, o serviço obstétrico dispunha de 
"30 leitos, sendo 15 para puérperas, 10 para gestantes, 4 para infectadas e 1 para isolamento". Em 1935, em opúsculo intitulado Histórico da Maternidade Dr. João Moreira, o mesmo médico indicava que, naquele ano, o estabelecimento contava com "33 leitos simples e 1 leito de Fowler, sendo 25 para puérperas, 5 para gestantes e 3 para infectadas”2 (Cals, 1935, p.4).

A apreciação do aumento da quantidade de leitos e, principalmente, de sua redistribuição na Maternidade, a partir dos anos 1930, fornece importantes indícios sobre a organização dos atendimentos médicos prestados nesse estabelecimento.

Tabela 1: Número de leitos e sua distribuição na Maternidade Dr. João Moreira nos anos 1920 e 1930

\begin{tabular}{|l|c|c|c|c|c|c|}
\hline Ano & $\begin{array}{c}\text { Total de } \\
\text { leitos simples }\end{array}$ & $\begin{array}{c}\text { Leitos para } \\
\text { gestantes }\end{array}$ & $\begin{array}{c}\text { Leitos para } \\
\text { puérperas }\end{array}$ & $\begin{array}{c}\text { Leitos para } \\
\text { infectadas }\end{array}$ & $\begin{array}{c}\text { Leitos para } \\
\text { operadas }\end{array}$ & $\begin{array}{c}\text { Leitos de } \\
\text { isolamento }\end{array}$ \\
\hline 1928 & 26 & 12 & 6 & 4 & 4 & - \\
\hline 1933 & 30 & 10 & 15 & 4 & - & 1 \\
\hline 1935 & 33 & 5 & 25 & 3 & - & - \\
\hline
\end{tabular}

Fonte: Elaborada pela autora com dados de Cals, set. 1928, p.9; Cals, fev. 1933, p.6-7; e Cals, 1935, p.4

De acordo com essa tabela, elaborada a partir das sucessivas informações fornecidas pelo doutor Cesar Cals a respeito da distribuição dos leitos da Maternidade Dr. João Moreira, se depreende a existência, por curto período de tempo, durante os anos 1930, de um leito de isolamento, instalação hospitalar geralmente dedicada a pacientes portadoras de doenças contagiosas. Muito embora o aparecimento do leito de isolamento não tivesse constituído pauta nos textos de autoria dos médicos do estabelecimento, é possível levantar a hipótese de que, quando funcionando nas dependências da Santa Casa de Misericórdia, o serviço obstétrico não tivesse necessidade dessa espécie de instalação pelo fato de provavelmente já existir uma congênere no prédio do Hospital da Misericórdia. Nesse sentido, a mudança para sede própria parece ter exigido da Maternidade um leito de isolamento, para o qual deveria ser encaminhada imediatamente a paciente que chegasse ao serviço obstétrico com algum sintoma de moléstia contagiosa. A extinção dessa instalação, ainda na primeira metade dos anos 1930, é fenômeno de difícil compreensão. Muito provavelmente, seus médicos teriam resolvido não mais receber mulheres portadoras de doenças contagiosas, supostamente levando em consideração o perigo que ofereciam às demais pacientes internadas ou a existência de serviços médicos locais, públicos e filantrópicos, dedicados a essa série específica de doentes. ${ }^{3}$

Observa-se também a supressão, a partir dos anos 1930, dos leitos de operadas, antes ali existentes em número de quatro. Essa modificação, cuja motivação não é explicitada pelos registros do serviço obstétrico, pode ter sido tributária de novas resoluções sobre a natureza dos atendimentos médicos prestados nesse estabelecimento. Com a transferência do serviço obstétrico para prédio próprio, suas antigas dependências do Hospital da Misericórdia parecem ter sido aproveitadas para a organização de uma enfermaria de cirurgia ginecológica, também chamada de Enfermaria de Mulheres. Importante marco, embora não definitivo, da bifurcação das especialidades médicas voltadas para o corpo da mulher, a saída do serviço obstétrico do prédio da Santa Casa de Misericórdia expressou, ao que parece, uma tendência de restringir os trabalhos da Maternidade Dr. João Moreira aos casos estritamente obstétricos, e, ao mesmo tempo, de deixar os atendimentos ginecológicos para a Enfermaria de Mulheres, a partir de então, em funcionamento no Hospital da Misericórdia. Ora, uma vez realizando 
majoritariamente operações de natureza obstétrica, muitas das quais consideradas mais simples do que as operações de ventre, nas quais se praticava incisões abdominais mais ou menos profundas, é plausível pensar que os médicos da Maternidade tivessem passado a ver os leitos exclusivos para mulheres operadas como dispensáveis, sendo que a sala para operadas muito provavelmente se fundiu com a sala das puérperas, cujos leitos aumentaram sensivelmente ao longo dos anos 1930.

As mudanças na organização espacial da instituição a partir de sua transferência para sede própria compreenderam igualmente a diminuição dos leitos para gestantes. Duas hipóteses não isoladas podem ser levantadas a esse respeito. Em primeiro lugar, é possível supor que os médicos do estabelecimento se tivessem dado conta de que a maioria das mulheres que o procuravam era composta de gestantes que, esgotados os recursos domiciliares da assistência ao parto, já chegavam ao serviço obstétrico na iminência da parturição, permanecendo, pois, pouquíssimo tempo na sala das gestantes ou mesmo suprimindo essa etapa dos atendimentos médicos. Acrescido ao fenômeno da busca tardia das parturientes pelos serviços da Maternidade Dr. João Moreira - denunciando, pois, que os serviços hospitalares não figuravam como a primeira opção no encaminhamento da assistência à parturição -, é plausível supor também que a diminuição dos leitos da sala das gestantes apresentasse o intuito de não permitir a entrada de mulheres pobres que, grávidas antes do termo, recorriam ao estabelecimento hospitalar como meio de conseguir alguns benefícios, como alimentos e roupas, fato que não deveria ser tão raro na capital cearense, mormente em tempos de seca.

Por fim, as mudanças na distribuição dos leitos da Maternidade ao longo dos anos 1930 deixam entrever o sensível aumento dos leitos dedicados às puérperas. Possivelmente, como já foi dito, o número desses leitos cresceu em virtude da agregação das unidades antes reservadas às operadas. Todavia, além disso, há que ter em conta que, se a maioria das pacientes que ali entrava já estava na iminência da parturição, e, portanto, quase não permanecia na sala das gestantes, essas mesmas mulheres passavam necessariamente pela sala das puérperas, compartimento em que deveriam permanecer no mínimo oito dias, período considerado suficiente para o restabelecimento do corpo e, principalmente, para anular as possibilidades de infecção puerperal. Mais frequentada, e por mais tempo, do que a sala das gestantes, a ala das puérperas passava a demandar, pois, maior número de leitos.

\section{A instrução de parteiras}

Também durante os anos 1930, os leitos da Maternidade Dr. João Moreira sofreram pequeno aumento. Não o suficiente, entretanto, para que o serviço obstétrico pudesse alcançar considerável porte, o que pode ser observado a partir da relação entre a estimativa da população-alvo do serviço obstétrico e o número de leitos disponíveis, e da comparação dessa relação com aquela apresentada pela Santa Casa de Misericórdia, na segunda metade do século XIX.

De acordo com o doutor Vinícius Barros Leal (1978, p.120), ao longo dos anos 1860, a relação de um leito da Santa Casa de Misericórdia para 240 habitantes era considerada, para aquele tempo, satisfatória, podendo "atender a uma população bem maior do que a existente na época, na capital". Nas décadas seguintes, essa relação tendeu a diminuir, chegando, já 
nos anos 1890, quase à metade do que fora trinta anos antes, fenômeno propiciado pela crescente positividade da saúde e concomitante valorização dos médicos, que paulatinamente iam incluindo em sua prática profissional os atendimentos hospitalares. Ora, se já no final do Oitocentos a relação de um leito da Santa Casa de Misericórdia para mais de 150 habitantes podia rapidamente ser considerada insuficiente, dado o aumento progressivo da população da capital cearense, imagine-se então o porte de um estabelecimento hospitalar que, durante as primeiras décadas do século passado, guardava a relação de um leito para mais de mil pessoas, como era o caso da Maternidade Dr. João Moreira.

Tabela 2: Número de leitos da Maternidade Dr. João Moreira relativamente à estimativa da população feminina de Fortaleza entre os anos 1920 e 1930

\begin{tabular}{|c|c|c|c|c|}
\hline Ano & $\begin{array}{c}\text { População de } \\
\text { Fortaleza }\end{array}$ & $\begin{array}{c}\text { Estimativa da população } \\
\text { feminina em idade } \\
\text { reprodutiva (1/3 do total) }\end{array}$ & $\begin{array}{c}\text { Total de leitos da } \\
\text { Maternidade }\end{array}$ & $\begin{array}{c}\text { Quantidade de mulheres } \\
\text { por leito }\end{array}$ \\
\hline 1928 & 120.817 & 40.272 & 26 & 1.548 \\
\hline 1933 & 136.386 & 45.462 & 30 & 1.515 \\
\hline 1935 & 143.277 & 47.759 & 33 & 1.447 \\
\hline
\end{tabular}

Fonte: Elaborada pela autora com dados de Cals, set. 1928, p.9; Cals, fev. 1933, p.6-7; e Cals, 1935, p.4

Tabela 3: Número de leitos da Santa Casa de Misericórdia de Fortaleza relativamente à população de Fortaleza na segunda metade do século XIX

\begin{tabular}{|c|c|c|c|}
\hline Ano & População de Fortaleza & $\begin{array}{c}\text { Total de leitos da } \\
\text { Santa Casa de Misericórdia }\end{array}$ & Número de pessoas por leito \\
\hline 1861 & 19.264 & 80 & 240 \\
\hline 1894 & 40.902 & 270 & 151 \\
\hline
\end{tabular}

Fonte: Elaborada pela autora com dados de Leal, 1978, p.120-122

Contrariamente à Santa Casa de Misericórdia, que figurava como um estabelecimento hospitalar dedicado, de fato, a amplas parcelas da população de Fortaleza acometidas pelas mais variadas moléstias, a Maternidade parecia não apresentar o intuito de receber grandes quantidades de mulheres que necessitassem de atendimentos obstétricos. Em nenhum momento, os médicos da Maternidade Dr. João Moreira manifestaram qualquer postura próxima à sistematização ou exclusividade do parto hospitalar, tal como já acontecia entre médicos do Rio de Janeiro e de São Paulo. ${ }^{4}$ Antes, apregoavam a necessidade de remodelar a assistência ao parto domiciliar, donde a instrução de parteiras realizada no interior do serviço obstétrico, através de seu Curso de Parteiras Diplomadas, ter sido considerada a função mais importante da instituição, e não propriamente a série de atendimentos médicos prestada à população em suas enfermarias.

Em 1915, quando começou a funcionar, o Curso de Parteiras Diplomadas tinha um ano de duração e exigia como pré-requisito essencial o saber ler e escrever, fato que, dados os altos índices de analfabetismo no Ceará, restringia enormemente o número de matrículas. Compreendendo três cadeiras - obstetrícia; anatomia, fisiologia e patologia dos órgãos geniturinários da mulher; e puericultura -, o curso se dividia entre aulas teóricas e práticas ministradas pelos médicos do hospital. Do ponto de vista dos médicos, o ensino obstétrico, como de resto o de todas as especialidades médicas, estava condicionado pela experiência clínica, em geral adquirida nas enfermarias hospitalares, junto às pacientes. Nesse sentido, 
o pequeno número de mulheres ali atendidas parecia constituir amostragem mais do que suficiente para que as futuras parteiras diplomadas obtivessem a prática do ofício e prosseguissem a remodelação do parto, que, na perspectiva dos médicos locais, continuava a se manter preferencialmente como evento domiciliar.

\section{Público-alvo da Maternidade Dr. João Moreira}

Estabelecimento hospitalar dedicado ao atendimento obstétrico de pequena parcela das mulheres da cidade, sobre cujos corpos os médicos promoviam a instrução de parteiras, a Maternidade era destino privilegiado de pacientes pobres. Em 1930, em resenha sobre o serviço obstétrico, o jornalista Theo Cabral (set. 1930, p.16-17) registrava:

A Maternidade recebe gratuitamente as mulheres indigentes que lhe batem à generosa porta a qualquer hora do dia ou da noite e fornece-lhes assistência obstétrica e médica, clínica e operatória, teto, cama, alimentos e medicação por oito dias, quando os partos são normais, e por tanto tempo quanto necessário para as que sofrem qualquer complicação patológica.

O tratamento gratuito oferecido em suas enfermarias, de duração indeterminada, compreendia, ademais, alimentação, roupas e lugar para dormir ${ }^{5}$. A acolhida no serviço obstétrico exigia em troca, da parte da paciente, a disponibilização quase irrestrita de seu corpo para a instrução de aprendizes de parteira e também, diga-se de passagem, para o aprofundamento da experiência clínica dos médicos, que ainda nesse período saíam das faculdades de medicina sem a devida prática do ofício ${ }^{6}$, o que incluía a realização de procedimentos obstétricos considerados arriscados. Internadas nas dependências do serviço obstétrico, a que recorriam em geral quando acometidas de alguma complicação que seus recursos usuais de assistência ao parto não conseguiam contornar, as mulheres humildes faziam a fama da Maternidade Dr. João Moreira de "hospital de parturiente pobre e distócica"7 (Aguiar, fev. 1933, p.3).

Muito embora a instituição constituísse serviço obstétrico voltado deliberadamente para as mulheres pobres da cidade, segundo o jornalista Theo Cabral (set. 1930, p.17), "não lhe aproveitam os serviços apenas as indigentes propriamente ditas. Muitas senhoras da classe média colhem os benefícios da Maternidade, que inclui a alimentação e necessários cuidados aos recém-nascidos". Registro raro, por meio do qual se vislumbra a possibilidade da convivência, nas enfermarias do serviço obstétrico, de mulheres pertencentes a diferentes extratos sociais ${ }^{8}$, a afirmativa do jornalista indica igualmente que os atendimentos ali praticados não se restringiam ao corpo das mulheres, podendo incluir cuidados com o corpo dos recém-nascidos.

Com efeito, as intervenções médicas sobre o fenômeno da maternidade não se limitavam aos momentos de gravidez, parto e puerpério, mas passavam a incluir significativamente o cuidado com as crianças. Além dos atendimentos médicos propriamente ditos referentes aos corpos infantis, realizados na clínica domiciliar ou nos consultórios do Instituto de Proteção e Assistência à Infância (Ipai), fundado na capital cearense em 1913, havia ainda práticas de instruir as mães a respeito dos cuidados com os filhos, em especial os recém-nascidos. Instrução, diga-se, de natureza racional, fundando as bases, em Fortaleza, do que se convencionou chamar de maternidade científica. 
De acordo com Martha Freire (2009, p.127),

Vários foram os canais de comunicação acionados, em todo o mundo, no processo de difusão do ideário da maternidade científica, iniciado no final do século XIX e intensificado nas primeiras décadas do século XX. Enquanto para as classes média a alta foram utilizados livros, folhetos e revistas ..., para a classe operária europeia tiveram grande importância os ambulatórios para distribuição de leite - de origem filantrópica e baseados no padrão 'consulta + conselho'.

As realizações de ações em prol da educação das mulheres, em especial as pobres, para o exercício da maternidade científica estiveram presentes tanto no Ipai quanto na Maternidade Dr. João Moreira. Nesta última, além da cadeira de puericultura, ministrada para as aprendizes de parteiras do serviço obstétrico e tornando-as verdadeiras educadoras das parturientes da cidade, havia ainda o gabinete médico da Maternidade, no qual muitas mães da cidade recebiam conselhos científicos sobre a arte de cuidar dos pequenos. ${ }^{9}$

Fosse para obter atendimento obstétrico ou conselhos sobre os filhos, as mulheres pobres que procuravam o estabelecimento hospitalar pareciam chegar, em maior número, por conta própria ou levadas por alguém de sua relação. Casos havia também em que algumas mulheres eram para lá encaminhadas pelos próprios médicos, fosse quando, durante o atendimento domiciliar, os doutores vislumbravam dificuldades que só poderiam ser superadas em enfermarias hospitalares, fosse quando, atendendo em instituições não especializadas, os médicos achavam por bem conduzir a paciente para o serviço obstétrico. Em meados dos anos 1930, o doutor Clóvis Barbosa de Moura (maio 1933, p.25) relatava episódio, por ele qualificado de pitoresco, protagonizado por uma senhora que chegara à Enfermaria de Mulheres da Santa Casa de Misericórdia entre finais dos anos 1920 e começo do decênio seguinte:

Mulher já madura entra para ser operada de tumor uterino, enviada por ilustrado colega, que não a examinara. Nega com admirável firmeza dos mártires cristãos, qualquer homenagem à Vênus.

Entretanto, o exame direto procedido pelo Dr. José Frota revela a existência de um feto de seis para sete meses.

A senhora vai ser transferida para a Maternidade; isto é um filho, diz-lhe o Dr. Frota, sem preâmbulo. A mulherzinha desapontada não se dá por vencida e recrimina-se, em forma de explicação: 'Bem que me disseram que os ares de Palmeiras eram danados para isto'.

Indício valoroso que permite entrever a divergência drástica entre dois médicos quanto ao diagnóstico do estado orgânico de uma mulher, considerada ora portadora de tumor uterino, ora grávida, o excerto dá conta de procedimento que pareceu ser comum depois da mudança da Maternidade Dr. João Moreira para sede própria, a saber, a transferência, por ordem médica, de pacientes da Enfermaria de Mulheres para o serviço obstétrico - tendo provavelmente o trajeto contrário também acontecido.

Além de encaminhadas à Maternidade por profissionais da saúde, como médicos e parteiras diplomadas, as pacientes podiam chegar ao estabelecimento hospitalar acompanhadas de autoridades policiais. Assim ocorria com as mulheres acusadas de crime de aborto ${ }^{10}$ ou infanticídio, conduzidas ao serviço obstétrico para a realização de exames confirmadores 
do parto e mesmo de tratamentos adequados quando apresentavam distúrbios orgânicos desenvolvidos das condições consideradas precárias em que se dera a parturição. Foi o que aconteceu com "Maria Neusa de Oliveira, solteira, com 18 anos de idade" que, em dias de novembro de 1932, dera à luz e, em seguida, supõe-se, assassinara seu rebento. Notificado do caso, o "Dr. Ubirajara Negreiros [delegado de polícia] tomou as providências necessárias, internando a parturiente na Maternidade em virtude de estar a mesma necessitando de cuidados médicos" (Tentativa..., 12 nov. 1932).

\section{Atendimentos prestados no serviço obstétrico}

Em resenha sobre a instituição, publicada na revista Ceará Médico referente ao mês de fevereiro de 1933, o doutor Cesar Cals (fev. 1933, p.8) informava que

O número de matriculadas [na Maternidade], que em 1915 foi de 385, atingiu em 1932 o respeitável número de 903 - É bem exato que este último ano foi anormal, em virtude da seca que fez convergir para a capital uma grande leva de flagelados. Desprezando-se, portanto, esse ano, busquemos a cifra de $1931 \mathrm{em}$ que as matriculadas se elevaram a 552, mais ou menos o dobro de 1915.

Ora, se do ponto de vista dos números brutos, a quantidade de mulheres ali atendidas anualmente, desde sua fundação até meados dos anos 1930, sofreu visível crescimento, comparando-se esses números com as cifras das sucessivas estimativas da população feminina de Fortaleza, algumas nuanças podem ser vislumbradas.

Tabela 4: Número de mulheres atendidas anualmente na Maternidade Dr. João Moreira em relação à estimativa da população feminina da cidade; média de mulheres atendidas por dia, entre 1915 e 1933

\begin{tabular}{|c|c|c|c|c|c|}
\hline Ano & $\begin{array}{c}\text { População de } \\
\text { Fortaleza }\end{array}$ & $\begin{array}{c}\text { Estimativa da } \\
\text { população } \\
\text { feminina } \\
\text { (1/3 do total) }\end{array}$ & $\begin{array}{c}\text { Mulheres } \\
\text { atendidas na } \\
\text { Maternidade ao } \\
\text { longo do ano }\end{array}$ & $\begin{array}{c}\text { Média de } \\
\text { mulheres } \\
\text { atendidas por dia }\end{array}$ & $\begin{array}{c}\text { \% anual sobre } \\
\text { a estimativa } \\
\text { da população } \\
\text { feminina }\end{array}$ \\
\hline 1915 & 73.223 & 24.407 & 285 & 0,7 & 1,16 \\
\hline 1916 & 74.330 & 24.776 & 293 & 0,8 & 1,18 \\
\hline 1917 & 75.454 & 25.151 & 325 & 0,8 & 1,29 \\
\hline 1918 & 75.595 & 25.198 & 313 & 0,8 & 1,24 \\
\hline 1919 & 77.753 & 25.917 & 396 & 1,52 \\
\hline 1920 & 78.536 & 26.187 & 359 & 0,9 & 1,37 \\
\hline 1921 & 81.160 & 27.053 & 345 & 1 & 1,27 \\
\hline 1922 & 104.852 & 34.950 & 369 & 1,1 & 1,13 \\
\hline 1923 & 107.357 & 35.785 & 406 & 1,1 & 1,14 \\
\hline 1924 & 109.922 & 36.640 & 421 & 1,1 & 1,08 \\
\hline 1925 & 112.549 & 37.516 & 407 & 1 & 1,01 \\
\hline 1926 & 115.239 & 38.413 & 391 & 1,3 & 1,23 \\
\hline 1927 & 117.995 & 39.331 & 485 & 1,3 & 1,22 \\
\hline 1928 & 120.817 & 40.272 & 495 & 1,4 & 1,24 \\
\hline 1929 & 123.707 & 41.235 & 514 & 1,4 & 1,26 \\
\hline 1930 & 126.666 & 42.222 & 532 & 1,4 & 1,26 \\
\hline 1931 & 129.827 & 43.275 & 546 & 2,4 & 2,03 \\
\hline 1932 & 133.066 & 44.355 & 903 & 2 & 1,65 \\
\hline 1933 & 136.386 & 45.462 & 753 & & \\
\hline
\end{tabular}

Fonte: Elaborada pela autora com dados de Cals, fev. 1933, p.19; e Cals, 1935, p.18 
Com efeito, mesmo que a quantidade de pacientes ali atendidas anualmente, entre 1915 e 1933, tenha mais do que duplicado, o estabelecimento hospitalar só recebia, por ano, em média, 1,3\% do total estimado de mulheres de Fortaleza, o que correspondia à média de 1,1 mulher atendida por dia no serviço obstétrico. Apenas em um ano, em 1932, a instituição atendeu em suas enfermarias número de pacientes correspondente a mais de $2 \%$ da estimativa da população feminina, o que foi suficiente para que os médicos do serviço obstétrico, com média diária de mais de duas pacientes atendidas, decretassem sua superlotação. Tal fenômeno se explica pela eclosão de forte seca no sertão do estado, fazendo da capital cearense o destino privilegiado de levas de retirantes que se aglomeravam no conjunto de instituições filantrópicas da cidade.

Sobre a natureza dos diversos atendimentos médicos prestados na Maternidade Dr. João Moreira, é possível colher algumas informações da Tabela 5, elaborada a partir das informações estatísticas fornecidas pelas resenhas assinadas pelo doutor Cesar Cals.

Tabela 5: Número de mulheres que deram à luz, foram tratadas por infecção puerperal e sofreram outros atendimentos relativamente à quantidade de mulheres atendidas na Maternidade Dr. João Moreira entre 1915 e 1933

\begin{tabular}{|c|c|c|c|c|c|c|c|}
\hline Ano & $\begin{array}{c}\text { Mulheres } \\
\text { atendidas }\end{array}$ & \multicolumn{2}{|c|}{$\begin{array}{c}\text { Mulheres que tiveram } \\
\text { assistência ao parto }\end{array}$} & \multicolumn{2}{c|}{$\begin{array}{c}\text { Mulheres atendidas por } \\
\text { infecção puerperal }\end{array}$} & \multicolumn{2}{c|}{$\begin{array}{c}\text { Mulheres que sofreram } \\
\text { outros atendimentos }\end{array}$} \\
\hline 1915 & 285 & 173 & $60,70 \%$ & 7 & $2,45 \%$ & 105 & $36,84 \%$ \\
\hline 1916 & 293 & 186 & $63,48 \%$ & 17 & $5,80 \%$ & 90 & $30,71 \%$ \\
\hline 1917 & 325 & 218 & $67,07 \%$ & 15 & $4,61 \%$ & 92 & $28,30 \%$ \\
\hline 1918 & 313 & 185 & $59,10 \%$ & 24 & $7,66 \%$ & 104 & $33,22 \%$ \\
\hline 1919 & 396 & 281 & $70,95 \%$ & 13 & $3,28 \%$ & 102 & $25,75 \%$ \\
\hline 1920 & 359 & 267 & $74,37 \%$ & 19 & $5,29 \%$ & 73 & $20,33 \%$ \\
\hline 1921 & 345 & 246 & $71,30 \%$ & 20 & $5,79 \%$ & 79 & $22,89 \%$ \\
\hline 1922 & 369 & 211 & $57,18 \%$ & 27 & $7,31 \%$ & 131 & $35,50 \%$ \\
\hline 1923 & 406 & 247 & $60,83 \%$ & 28 & $6,89 \%$ & 131 & $32,26 \%$ \\
\hline 1924 & 421 & 306 & $72,68 \%$ & 8 & $1,90 \%$ & 107 & $25,41 \%$ \\
\hline 1925 & 407 & 302 & $74,20 \%$ & 12 & $2,94 \%$ & 93 & $22,85 \%$ \\
\hline 1926 & 391 & 304 & $77,74 \%$ & 10 & $2,55 \%$ & 77 & $19,69 \%$ \\
\hline 1927 & 485 & 354 & $72,98 \%$ & 13 & $2,68 \%$ & 118 & $24,32 \%$ \\
\hline 1928 & 495 & 365 & $73,73 \%$ & 9 & $1,81 \%$ & 121 & $24,44 \%$ \\
\hline 1929 & 514 & 420 & $81,71 \%$ & 10 & $1,94 \%$ & 84 & $16,34 \%$ \\
\hline 1930 & 532 & 438 & $82,33 \%$ & 9 & $1,69 \%$ & 85 & $15,97 \%$ \\
\hline 1931 & 546 & 440 & $80,58 \%$ & 13 & $2,38 \%$ & 93 & $17,03 \%$ \\
\hline 1932 & 903 & 748 & $82,83 \%$ & 11 & $1,21 \%$ & 144 & $15,94 \%$ \\
\hline 1933 & 753 & 602 & $79,94 \%$ & 13 & $1,72 \%$ & 138 & $18,32 \%$ \\
\hline
\end{tabular}

Fonte: Elaborada pela autora com dados de Cals, fev. 1933, p.19-21; e Cals, 1935, p.18

Depreende-se desse quadro que a assistência ao parto, como era de esperar, constituiu o atendimento médico predominante nas enfermarias da instituição. Correspondendo, em todo o período de estudo, a mais de 50\% do total dos atendimentos prestados no serviço obstétrico, a assistência ao parto sofreu visível aumento a partir de 1929, fenômeno possivelmente tributário da maior procura do estabelecimento hospitalar por parte de gestantes e parturientes e, simultaneamente, da diminuição dos atendimentos ginecológicos que, a partir daquele ano, passaram a ser divididos com a Enfermaria de Mulheres da Santa Casa de Misericórdia. 
A preocupação dos médicos do estabelecimento em discriminar as pacientes recebidas por infecção puerperal indica que os procedimentos terapêuticos dedicados a essa enfermidade tomavam parte importante dos trabalhos da Maternidade. Importa ressaltar, a respeito dos números apresentados de infectadas, a não inclusão das mulheres infectadas que contraíram a moléstia no interior do estabelecimento hospitalar, estas últimas inseridas, pois, nas cifras das gestantes. O conjunto significativo das demais mulheres que davam entrada no serviço obstétrico sem ter seus atendimentos discriminados pode incluir pacientes com moléstias gravídicas que, muito embora tivessem recebido tratamento no estabelecimento hospitalar, findaram por não dar à luz em suas enfermarias; e também puérperas que apresentavam disfunções orgânicas distintas da infecção puerperal. Podem igualmente estar incluídas nesse vasto grupo as mulheres com problemas ginecológicos que, a despeito do funcionamento da Enfermaria de Mulheres da Santa Casa de Misericórdia, ainda eram recebidas pela Maternidade Dr. João Moreira, muito embora, supomos, em quantidade menor.

Relativamente à eficiência dos atendimentos lá prestados, a Tabela 6 fornece informações importantes.

Tabela 6: Número de altas e de falecimentos em relação às mulheres atendidas na Maternidade Dr. João Moreira entre 1915 e 1933

\begin{tabular}{|c|c|c|c|c|c|c|c|c|c|}
\hline Ano & $\begin{array}{l}\text { Mulheres } \\
\text { atendidas }\end{array}$ & \multicolumn{3}{|c|}{ Altas curadas } & \multicolumn{2}{|c|}{ Altas a pedido } & \multicolumn{2}{l|}{ Altas melhoradas } & \multicolumn{2}{l|}{ Falecimentos } \\
\hline 1915 & 285 & 213 & $74,73 \%$ & 43 & $15,08 \%$ & 6 & $2,10 \%$ & 7 & $2,45 \%$ \\
\hline 1916 & 293 & 245 & $79,28 \%$ & 39 & $12,62 \%$ & 6 & $1,94 \%$ & 7 & $2,26 \%$ \\
\hline 1917 & 325 & 262 & $77,74 \%$ & 35 & $10,38 \%$ & 14 & $4,15 \%$ & 9 & $2,67 \%$ \\
\hline 1918 & 313 & 284 & $86,06 \%$ & 24 & $7,27 \%$ & - & - & 4 & $1,21 \%$ \\
\hline 1919 & 396 & 366 & $82,35 \%$ & 17 & $4,16 \%$ & - & - & 5 & $1,22 \%$ \\
\hline 1920 & 359 & 350 & $92,34 \%$ & 18 & $4,74 \%$ & - & - & 6 & $1,58 \%$ \\
\hline 1921 & 345 & 321 & $91,71 \%$ & 8 & $2,28 \%$ & 1 & $0,28 \%$ & 8 & $2,28 \%$ \\
\hline 1922 & 369 & 351 & $92,12 \%$ & 18 & $4,72 \%$ & 1 & $0,26 \%$ & 4 & $1,04 \%$ \\
\hline 1923 & 406 & 359 & $86,92 \%$ & 27 & $6,53 \%$ & 1 & $0,24 \%$ & 12 & $2,90 \%$ \\
\hline 1924 & 421 & 388 & $89,19 \%$ & 27 & $6,20 \%$ & - & - & 7 & $1,60 \%$ \\
\hline 1925 & 407 & 371 & $88,33 \%$ & 19 & $4,52 \%$ & - & - & 11 & $2,61 \%$ \\
\hline 1926 & 391 & 379 & $92,43 \%$ & 19 & $4,63 \%$ & - & - & 3 & $0,73 \%$ \\
\hline 1927 & 485 & 448 & $90,68 \%$ & 18 & $3,64 \%$ & 2 & $0,40 \%$ & 13 & $2,63 \%$ \\
\hline 1928 & 495 & 461 & $90,74 \%$ & 21 & $4,13 \%$ & 3 & $0,59 \%$ & 11 & $2,16 \%$ \\
\hline 1929 & 514 & 504 & $95,81 \%$ & 7 & $1,33 \%$ & - & - & 5 & $0,95 \%$ \\
\hline 1930 & 532 & 511 & $94,28 \%$ & 4 & $0,73 \%$ & 1 & $0,18 \%$ & 3 & $0,55 \%$ \\
\hline 1931 & 546 & 552 & $97,01 \%$ & 2 & $0,35 \%$ & - & - & 6 & $1,05 \%$ \\
\hline 1932 & 903 & 864 & $94,73 \%$ & 10 & $1,09 \%$ & - & - & 8 & $0,87 \%$ \\
\hline 1933 & 753 & 735 & $93,86 \%$ & 13 & $1,66 \%$ & 4 & $0,51 \%$ & 14 & $1,78 \%$ \\
\hline
\end{tabular}

Fonte: Cals, 1933, p.19

Os índices de altas curadas na Maternidade Dr. João Moreira, cuja menor cifra deu-se no primeiro ano de funcionamento do estabelecimento, tendeu a aumentar ao longo dos anos, mantendo-se curiosamente acima dos 93\% durante o período em que o serviço obstétrico passou a funcionar em sede própria. A categoria das altas melhoradas, relativas às pacientes que deixavam o estabelecimento hospitalar ainda não completamente restabelecidas, mas tendendo à cura, se manteve ente $2 \%$ e $4 \%$ nos três primeiros anos de atividade da instituição e guardou nos demais anos cifras inferiores a 1\%, indicando, pois, que as mulheres 
pareciam permanecer mais tempo nas enfermarias da Maternidade, de onde só saíam, na maioria, quando seus estados orgânicos se apresentavam totalmente restituídos. Os índices de falecimento apresentaram variação irregular, não alcançando, todavia, em nenhum dos anos em estudo, a taxa de $3 \%$.

\section{Disciplina hospitalar, resistências femininas}

Se a análise estatística dos atendimentos prestados na Maternidade Dr. João Moreira permite concluir pela visível eficiência do serviço obstétrico, os números deixam entrever, por outro lado, a existência de relutâncias por parte das mulheres diante dos procedimentos realizados no serviço obstétrico. Com efeito, a alusão, nas próprias estatísticas do estabelecimento, de uma modalidade de alta denominada a pedido vem reforçar o fato de que as mulheres ali atendidas nem sempre eram completamente dóceis aos expedientes terapêuticos realizados nas enfermarias. Referidas como os casos em que as pacientes rejeitavam explicitamente os tratamentos prescritos e abandonavam o estabelecimento hospitalar, as cifras de altas a pedido flutuaram entre $7 \%$ e 15\% durante os quatro primeiros anos de atividade do serviço obstétrico, sobrevindo em seguida sua progressiva diminuição, que, a partir 1929, já em sede própria, não ultrapassaram 1,6\%, embora, importa ressaltar, nunca tivessem deixado de existir.

Enquanto unidade hospitalar moderna, a Maternidade Dr. João Moreira seguia orientação disciplinar embasada não só na distribuição espacial de suas pacientes, mas também no estreito acompanhamento de seus gestos. Assim, se na maioria dos casos clínicos o pessoal hospitalar se empenhava em acompanhar os mínimos movimentos das mulheres internadas no serviço obstétrico, ocasiões havia em que os médicos lançavam mão de práticas terapêuticas que demandavam a completa imobilização do corpo das pacientes. Em texto publicado na revista Ceará Médico, em meados de 1917, o doutor Manuelito Moreira (abr.-jun. 1917) relatava o caso da senhora "M. R. C., branca, 31 anos, brasileira, cearense, moradora à rua S. Luiz, casada, doméstica" (p.24), acometida de moléstia gravídica denominada placenta prévia. A paciente deu entrada na Maternidade no dia 16 de junho de 1915, aos nove meses de gestação, apresentando fortes hemorragias uterinas que se acentuaram após o parto. Diante da gravidade do quadro,

Sem perda de tempo, foi praticado o tamponamento uterovaginal a Duhrssen, que, como recurso heroico nestes casos, conseguiu a hemostasia [estancamento da hemorragia].

...

A parturiente foi deitada em seu leito em posição inclinada, (a cabeça em plano inferior), tendo sido limitada a circulação por meio de ataduras, ligando as raízes dos membros.

O tamponamento uterovaginal foi retirado após 28 horas, tendo a hemorragia cedido completamente (Moreira, abr.-jun. 1917, p.25).

O tamponamento uterovaginal, inserção densa de gazes e substâncias medicamentosas no interior do útero e do canal vaginal, expediente terapêutico com a finalidade de estancar os sangramentos uterinos, foi mantido no corpo da senhora M. R. C. durante 28 horas, ao longo das quais a paciente permaneceu no leito em posição inclinada, tendo os braços e as 
pernas completamente imobilizados por meio de ataduras. Por mais de um dia, portanto, a paciente não apenas ficou impedida de andar, mas também de realizar mínimos movimentos.

Os registros dos controles terapêuticos por meio da distribuição espacial das pacientes e do cerceamento dos movimentos do corpo são os mesmos que deixam entrever, todavia, as resistências das mulheres diante da disciplina hospitalar. Em caso clínico publicado na revista Norte Médico, referente ao mês de setembro de 1915, o doutor Cesar Cals (set. 1915, p.15) dava notícia da paciente "M. C. C., 31 anos de idade, branca, natural do Rio G. do Norte, residente em Fortaleza, casada, doméstica, multípara (9 partos normais) - Entrou para a Maternidade a 12 de julho de 1915. Diagnóstico - Infecção puerperal datando de 7 dias". Ao cabo da segunda semana de tratamento,

a doente, que até 2 horas da tarde de 27 de julho passava regularmente, com tendência à cura ..., e guardava absoluto repouso, ilude a vigilância da enfermeira e vai até o corredor, onde é acometida súbita e abruptamente de dispnéia intensa, cianose dos lábios e da face, suores profusos, algidez das extremidades, pulso rápido, tendo nesta ocasião colocado uma das mãos sobre o coração, como que acusando angústia extrema; sentase então em uma cadeira que lhe é oferecida, na qual é transportada para o leito, onde falece às 6 horas da tarde, 4 horas depois do acidente, apesar do tratamento enérgico e mui criteriosamente empregado por seu médico assistente Dr. Gonçalves Moreira.

A descrição desse caso clínico, na qual se atribui a causa da morte da paciente a um acidente considerado incontornável denominado embolia pulmonar, revela o intuito de manter as pacientes da Maternidade sob regime de vigilância. Regime que, no entanto, muitas vezes se manifestava falho, já que a senhora M. C. C. conseguiu, diga-se, aliás, com significativa facilidade, ficar livre dos olhares da enfermeira e caminhar pelas dependências do serviço obstétrico.

\section{Equipe hospitalar}

Restam ainda algumas considerações sobre o corpo profissional da Maternidade Dr. João Moreira. O Almanaque do Ceará para o ano de 1916 indicava os seguintes médicos que prestavam serviços na Maternidade Dr. João Moreira: "Médico e fundador - Dr. Manoelito Moreira. Ajudante - Dr. Cesar Cals de Oliveira. Auxiliares - Drs. Carlos da Costa Ribeiro e Antonio Gonçalves Moreira" (Maternidade..., 1915, p.124). O doutor Manuelito Moreira, fundador da instituição, manteve-se em sua direção clínica até 1923, quando, por conta de compromissos políticos, se mudou para o Rio de Janeiro. Desde então, o serviço obstétrico passou a ser dirigido pelo doutor Cesar Cals, que, ainda em 1923, convidou o doutor José Ribeiro da Frota para assumir o posto de vice-diretor do estabelecimento. Ambos permaneceram nesses cargos até, pelo menos, o final dos anos 1930.

Além desses médicos, vários outros tiveram passagem pela Maternidade. O doutor Carlos da Costa Ribeiro pertenceu a seu corpo clínico apenas durante os primeiros anos de funcionamento do estabelecimento, tendo depois se ocupado, no final dos anos 1910, com a assunção da Inspetoria de Higiene do Estado e, em seguida, com a fundação do Instituto Pasteur de Fortaleza. Por sua vez, o doutor Gonçalves Moreira ali permaneceu pouco tempo como médico, já que no final dos anos 1910 transferiu residência para outra localidade. Ainda 
nesse decênio, tem-se notícia de que o doutor Antonio Messiano assumiu, no período de 1917, o serviço de infectadas do estabelecimento. No começo dos anos 1930, a Maternidade contava com os serviços da doutora Maria de Souza Cavalcante e do doutor J. Deusdedit; na segunda metade desse decênio, os doutores Juvenil Hortencio e Osvaldo Soares passaram a fazer parte de seu corpo clínico.

Muito embora a maioria dos escritos relativos às atividades da Maternidade Dr. João Moreira aludissem prioritariamente às atividades desempenhadas pelos médicos que ali prestavam atendimento, importa ressaltar a presença de outros profissionais que também trabalhavam no serviço obstétrico. Nesse sentido, enquanto esteve alojada nas dependências da Santa Casa de Misericórdia, a Maternidade parece ter contado com algumas enfermeiras daquele hospital, cujas identificações, bem como formações e/ou licenças profissionais são de difícil conhecimento. A partir de 1916, quando o serviço obstétrico começou a formar parteiras diplomadas, algumas dessas profissionais passaram a trabalhar na própria Maternidade.

Nos anos 1930, as "irmãs franciscanas, sendo a superiora a madre Escolástica Maria" (Maternidade..., 1930, p.167), prestavam importantes serviços ao estabelecimento hospitalar, encarregando-se, entre outras coisas, dos serviços internos de organização, arrumação e limpeza. Também nesse decênio, o jornalista Theo Cabral (set. 1930, p.18) escrevia que

Nesta breve resenha sobre o que é e o que representa, em Fortaleza, a Maternidade Dr. João Moreira, seria uma injustiça esquecer os nomes de Irmã Augustinha, que dirige a administração das assistentes Sras. Joana Ferreira e Raimunda Monteiro, parteiras diplomadas, que realizam, com tanta competência quanto dedicação, o serviço de partos.

Antes de mais, importa ressaltar que as parteiras diplomadas não eram consideradas aptas a realizar a assistência ao parto de maneira indiscriminada. A sutil divisão das dinâmicas do corpo feminino entre normais e patológicas, segundo a moderna obstetrícia, tinha por corolário a instauração de limites à assistência dessas parteiras, que, diante de determinados estados mórbidos, nada poderiam fazer.

As parteiras diplomadas que trabalhavam na clínica hospitalar, como as citadas anteriormente, eram "superintendidas pelos médicos, que são chamados, de dia ou de noite sempre que surge um caso delicado, que lhes reclame a presença e cuidados de obstetrícia e cirurgia" (Cabral, set. 1930, p.17). As assistentes internas à Maternidade Dr. João Moreira tinham por incumbência receber as mulheres que chegavam ao serviço obstétrico, realizar os primeiros exames, dar pareceres diagnósticos, assistir aos partos considerados normais, auxiliar os médicos por ocasião de parturições complicadas, realizar os acompanhamentos médicos e terapêuticos dedicados às gestantes e puérperas que se encontravam nas enfermarias do serviço obstétrico etc. ${ }^{11}$

Inseridas em posição hierarquicamente inferior aos médicos, nada garantia que as parteiras diplomadas da institiuição tivessem deixado de realizar procedimentos considerados inadequados para sua assistência, em especial nas crises de urgência. O regime de trabalho integral a que se submetiam, em contraste com o parco tempo despendido pelos médicos no serviço obstétrico ${ }^{12}$, atraía as mulheres cearenses, que ainda cultivavam desconfianças com relação a estabelecimentos hospitalares, e conferia a essas profissionais considerável margem para proceder aos atendimentos da maneira como melhor lhes aprouvesse. 
Cientes dessa situação de empoderamento das parteiras diplomadas em pleno templo da obstetrícia moderna na cidade, os médicos raramente reconheciam o trabalho dessas profissionais. Em todos os textos publicados na revista do Centro Médico Cearense sobre a Maternidade Dr. João Moreira, sobressaía a competência dos médicos, ou melhor, seus sucessos em atendimentos considerados mais difíceis. Os atendimentos ordinários e mesmo os extraordinários que contavam com os préstimos das parteiras diplomadas não eram dignos de registro. Diferente disso, as menções a assistentes diplomadas do serviço obstétrico, quando apareciam, ganhavam tom depreciativo.

Em texto publicado na revista Ceará Médico sobre a realização do toque vaginal durante o parto e seus riscos quanto à contração da infecção puerperal, colocando-se na contramão do que a obstetrícia realizada nos estados brasileiros da região Sul pregava, o diretor da Maternidade não detectava maiores problemas quanto à realização desse procedimento, advogando, aliás, o caráter prescindível do uso de luvas. Tomando por base seus estudos estatísticos, o doutor Cesar Cals (set. 1934, p.20) comprovava seu posicionamento:

A nossa prática, porém, no Ceará não concorda com o que está escrito. Ou estamos nós errados ou são especialíssimas as condições do Ceará, de molde a diminuir a virulência dos germes responsáveis pela infecção puerperal.

...

Na Maternidade Dr. João Moreira que dirigimos e por onde já passaram mais de 8 milhares de gestantes é sistemática a prática do toque vaginal sem que o número de infectadas ali ascenda a proporções assustadoras

Em sua opinião, apenas em um caso, o de uma mulher infectada em 1933, o toque vaginal ou outras práticas corporais internas puderam ser aventados como hipótese para a contração do estado mórbido, e ainda assim não por conta do procedimento em si, mas devido ao fato de que "a assistente que lhe assistiu estava com um pequeno furúnculo no dedo" (Cals, 1935, p.8). Destaque-se o fato de que se tratava de uma parteira diplomada, e não de um médico, configurando uma ocasião em que a falha nos atendimentos médicos prestados no interior da Maternidade Dr. João Moreira, longe de constituir responsabilidade deles, recaiu sobre as assistentes que, importa lembrar, haviam sido por eles instruídas.

\section{Considerações finais}

Médicos, enfermeiras, parteiras diplomadas, irmãs de caridade participaram, pois, do funcionamento das distintas nuanças daquele que foi um dos primeiros núcleos formadores da ciência obstétrica no Ceará: a Maternidade Dr. João da Rocha Moreira. Entendemos que a análise da organização espacial desse estabelecimento, em especial suas implicações sobre a distribuição dos corpos, sobre os regimes de cura e disciplina, sobre os critérios de entrada e saída de suas enfermarias, sobre as práticas médicas terapêuticas e pedagógicas, sobre a relação de cumplicidade entre ensino médico e pobreza jogam luz sobre questões imprescindíveis acerca da história da ciência médica, da história das instituições hospitalares e da história da assistência ao parto. Histórias, ao mesmo tempo, descontínuas, cruzadas e complementares; recheadas de desvios e reveses. 


\section{NOTAS}

${ }^{1}$ Em 1913, foi fundada em Fortaleza a agremiação médica mais atuante e mais duradoura do século XX, o Centro Médico Cearense. Em encontros mensais, seus membros apresentavam pesquisas demográficas, faziam considerações sobre o estado sanitário da cidade, formavam comissões específicas para a realização de estudos etiológicos e também para pressionar as instâncias governamentais e os estabelecimentos particulares em prol da concretização de medidas comprometidas com a saúde da população. Não raramente, as questões levantadas nas reuniões ganhavam a forma de textos que eram remetidos para a redação do periódico oficial da agremiação, a revista Norte Médico, renomeada em 1917 Ceará Médico.

${ }^{2}$ Introduzido na Maternidade em meados da década de 1930, o leito de Fowler consiste numa espécie de cama hospitalar de alta flexibilidade. Infelizmente, não conseguimos apurar mais informações sobre seus usos específicos no interior do serviço obstétrico.

${ }^{3}$ Em 1922, o Serviço de Saneamento e Profilaxia Rural, órgão público criado a partir de contrato selado entre o governo do estado do Ceará e o governo da União, organizou o Serviço de Lepra e Doenças Venéreas, mantendo um posto de trabalho em Fortaleza; e em 1929 foi fundado o Leprosário Antônio Diogo, na localidade de Canafístula, mantido pela iniciativa filantrópica.

${ }^{4}$ De acordo com Maria Lúcia de Barros Mott (dez. 2002, p.198), no Brasil, a "indicação do hospital como lugar ideal e seguro para as mulheres darem à luz é uma recomendação que passa a ser divulgada na literatura médica, com mais ênfase, a partir da década de 1930". Emitidos, prioritariamente, pelos médicos do Rio de Janeiro e de São Paulo, os discursos em prol da hospitalização sistemática do parto parecem não ter repercutido entre os médicos da capital cearense, pelo menos até meados dos anos 1930.

${ }^{5}$ Fabíola Rohden (2001, p.30) lembra que "Nancy Theriot enfatiza que não se deve considerar a relação entre mulheres pacientes e establishment médico com base no modelo da vitimização, como fizeram especialmente os primeiros estudos que recuperavam esta história ... Theriot afirma que as mulheres não eram apenas vítimas da ciência médica: eram também capazes de usá-la de acordo com os seus interesses".

${ }^{6}$ De acordo com Ana Paula Vosne Martins (2004, p.151), "somente no final do século XIX os estudantes de medicina começaram a ter um ensino de obstetrícia voltado para a clínica, aprendendo a realizar exames, a reconhecer posições e apresentações do feto, a utilizar o instrumental obstétrico e a fazer cirurgias. Mesmo não sendo o ideal, o sistema de enfermarias proporcionou aos estudantes as condições para observar o corpo feminino e saber agir tanto nos partos naturais quanto nas distocias. Somente no século XX as faculdades de medicina passaram a ter um espaço adequado ao ensino das clínicas obstétrica e ginecológica, quando começaram a ser construídas as primeiras maternidades no Brasil. Até então, o ensino teórico foi mais privilegiado e com ele difundiu-se, entre os estudantes e futuros médicos, boa parte do conhecimento das duas especialidades produzido na Europa e propagado pelos alunos nas suas teses de conclusão de curso".

${ }^{7}$ Distócica era a parturiente que apresentava distocia, dificuldade mecânica que pode surgir na hora do parto, dificultando a expulsão do feto.

${ }^{8}$ Importa ressaltar que, a partir de 1928, com a fundação das primeiras casas de saúde da capital cearense, a Casa de Saúde São Lucas e a Casa de Saúde Dr. Cesar Cals, ambas destinadas a pacientes pagantes, as mulheres de razoável condição financeira passaram a contar com atendimento hospitalar diferenciado caso apresentassem durante o parto complicações não contornáveis pelos recursos da assistência domiciliar.

9 Importa ter em mente que nem sempre os conselhos a respeito da 'maternidade científica' eram automaticamente aceitos pelas mulheres. Martha Freire $(2009$, p.131) lembra que "o processo de construção da maternidade científica, assim como o de outros campos do conhecimento, não se deu de maneira impositiva ou acrítica, mas envolveu negociações conforme os interesses tanto dos médicos quanto das mulheres, e revelou-se ainda permeável à influência de outras forças sociais, como o discurso da Igreja Católica e a pressão da indústria de consumo. Assim, às tentativas de normatização do exercício da maternidade por parte dos médicos, as respostas das mulheres envolveram simultaneamente incorporações e rejeições dos conceitos científicos, adaptando-os aos próprios saberes e atualizando um repertório particular quanto à criação dos seus filhos".

${ }^{10}$ Algumas vezes envolvida nos trâmites da medicina legal, quando seus médicos realizavam exames para confirmar ou não determinados procedimentos, como defloramentos, abortos e infanticídios, a Maternidade Dr. João Moreira não realizava abortos. A despeito de algumas vozes de médicos locais em prol dessa prática como medida biopolítica, os profissionais da instituição se colocavam contra esse procedimento, que muitas vezes foi associado às práticas das parteiras ditas curiosas, e, portanto, digno de reprovação e combate. 
${ }^{11}$ Já as parteiras diplomadas que realizavam a clínica domiciliar, diante de circunstâncias em que não eram consideradas aptas a proceder, teriam por obrigação encaminhar a paciente para um hospital ou solicitar a presença de um médico, único profissional autorizado a fazer uso dos recursos obstétricos exigidos nessas ocasiões. Insinuava-se, pois, uma importante incumbência a ser assumida pelas parteiras diplomadas, a saber, intermediar os contatos entre médicos e mulheres, ainda precários na capital cearense daquele período, e, ademais, instituir a Maternidade Dr. João Moreira como espaço privilegiado na cidade para a resolução dos estados patológicos ligados à gestação, ao parto e ao puerpério.

${ }^{12} \mathrm{O}$ doutor Cesar Cals, por exemplo, durante o período em que prestava serviços à Maternidade Dr. João Moreira, assumindo até o cargo de seu diretor, continuava a realizar atendimentos médicos em seu consultório e no domicílio de algumas pacientes; em 1924, assumiu o cargo de deputado estadual e passou a dirigir, a partir de 1929, a Casa de Saúde Dr. Cesar Cals, estabelecimento hospitalar destinado a pensionistas. Certamente, sobrava pouco tempo para dedicação mais estreita à Maternidade Dr. João Moreira.

\section{REFERÊNCIAS}

AGUIAR, Virgílio de.

A natalidade e a natimortalidade. Ceará Médico, Fortaleza, n.12, p.33. dez. 1933.

AGUIAR, Virgílio de.

A Maternidade Dr. João Moreira. Ceará Médico, Fortaleza, n.2, p.1-3. fev. 1933.

CABRAL, Theo.

Benemérita instituição: o que é e o que representa a Maternidade Dr. João Moreira. Ceará Médico, Fortaleza, n.9, p.15-18. set. 1930.

CALS, Cesar.

Histórico da Maternidade Dr. João Moreira. In: Primeiro Congresso Médico Cearense. Fortaleza: Imprensa Oficial. 1935.

CALS, Cesar.

O toque vaginal durante o parto e a infecção puerperal. Ceará Médico. Fortaleza, n.9, p.19-23. set. 1934 .

CALS, Cesar.

Maternidade Dr. João Moreira: 18o ano de funcionamento. Ceará Médico, Fortaleza, n.2, p.6-22. fev. 1933.

\section{CALS, Cesar.}

A Maternidade Dr. João Moreira. Ceará Médico, Fortaleza, n.1, p.9-12. set. 1928.

CALS, Cesar.

Embolia pulmonar no decurso da infecção puerperal. Norte Médico, Fortaleza, n.1, p.15-17. set. 1915.

FOUCAULT, Michel.

História da sexualidade 1: a vontade de saber. São Paulo: Graal. 2007.

FREIRE, Maria Martha de Luna.

Mulheres, mães e médicos: discurso maternalista no Brasil. Rio de Janeiro: Editora FGV. 2009.
LEAL, Vinícius Barros.

História da medicina no Ceará. Fortaleza: Secretaria de Cultura, Desporto e Promoção Social. 1978.

MARTINS, Ana Paula Vosne.

Visões do feminino: a medicina da mulher nos séculos XIX e XX. Rio de Janeiro: Editora Fiocruz. 2004.

MATERNIDADE...

Maternidade Dr. João Moreira e Casa de Saúde Dr. Cesar Cals. Almanaque do Ceará para o ano de 1931. Fortaleza, [s.n.]. p.167. 1930.

MATERNIDADE...

Maternidade Dr. João Moreira. Almanaque do Ceará para o ano de 1916. Fortaleza: [s.n.]. p.123-124. 1915.

MOREIRA, Manuelito.

Placenta prévia: hemorragia do delivramento. Ceará Médico, Fortaleza, n.2, p.24-25. abr.-jun. 1917.

MOTT, Maria Lúcia de Barros.

Assistência ao parto: do domicílio ao hospital (1830-1960). Projeto História, São Paulo, n.25, p.197-219. dez. 2002.

MOURA, Clóvis Barbosa de.

Movimento geral da 6 6 - Enfermaria da Santa Casa de Misericórdia de Fortaleza, de 11 de junho de 1929 a 31 de julho de 1932. Ceará Médico, Fortaleza, n.5, p.24-25. maio 1933.

ROHDEN, Fabíola.

Uma ciência da diferença: sexo e gênero na medicina da mulher. Rio de Janeiro: Editora Fiocruz. 2001.

TENTATIVA...

Tentativa de infanticídio: deu à luz a criança e enterrou-a no quintal: o Caso na Polícia. O Nordeste, Fortaleza, p.3. 12 nov. 1932.

\section{$\rightarrow \rightarrow+<<$}

